\title{
Mutation Status of p53 Gene in Oral Squamous Cell Carcinoma
}

\author{
Branka Popović ${ }^{\text {, Biljana Jekić2 }}$, Drago Jelovac 3 , Ivana Novaković ${ }^{2}$ \\ 1 Institute of Human Genetics, School of Dentistry, University of Belgrade, Belgrade, Serbia; \\ ${ }^{2}$ Institute of Human Genetics, School of Medicine, University of Belgrade, Belgrade, Serbia; \\ ${ }^{3}$ Clinic of Maxillofacial Surgery, School of Dentistry, University of Belgrade, Belgrade, Serbia
}

\begin{abstract}
SUMMARY
Introduction p53 gene is the most common tumor suppressor gene involved in pathogenesis oral squamous cell carcinoma (OSCC). Protein product of p53 gene contributes to cell cycle control and apoptosis. p53 gene mutations may lead to uncontrolled cell growth. The aim of this study was to determine the incidence of mutation in DNA-binding domain of $\mathrm{p} 53$ gene.

Materials and Methods In the 60 specimens, the presence of point mutation in exons 5, 6, 7 and 8 was detected using PCR-SSCP method. To confirm the presence of $\mathrm{p} 53$ mutation found by SSCP method, five samples were analyzed by sequencing of exon 5 .

Results Point mutation affecting exons 5, 6, 7 and 8 were found in $60 \%$ of analyzed samples. A higher incidence of mutation was detected in exon 7 and 8 (60\%), than in exon 5 and 6 . Sequencing of exon 5 , confirmed the presence of mutations revealed by SSCP method. Study of associations showed an increase of p 53 mutations in poor differentiated and carcinoma of higher clinical stages.

Conclusion p53 gene is one of major factor in control of cell cycle and has important role in pathogenesis of oral squamous cell carcinoma
\end{abstract}

Keywords: p53 gene; point mutation; oral squamous cell carcinoma

\section{INTRODUCTION}

According to statistical data, head and neck squamous cell carcinomas (HNSSCs), on the scale of incidence of all human tumors, are on the $6^{\text {th }}$ position, wheras $50 \%$ of these tumors are located in oral region. Despite development in the last decades in the prevention and efficiant surgical resections, as well as adequate radio and chemotherapy, five-year survival rate still remains the same (about 50\%) [1]. Lack of simptomatology, rapid growth and early metastasis are the reasons of the bad course of disease. Different scrinning methods and introduction of molecular-genetic analyses could be of great importance during the preclinical, asimptomatic stage of disease to provide possible better prognosis.

One of the pivotal molecular-genetics markers, introduced in the control of proliferation in about $60 \%$ tumors of the head and neck, is p53 tumor suppressor gene [2]. Normal function of p53 gene could be lost by exposing oral mucosa to different cancerogenic agetns (e.g. smoking, alcohol...). p53 gene named as "guardian of genome”, has a role to stop the proliferation of cell with genetic lesions, giving the time to cells to repair damaged genetic material. Contrary, cells with unrepaired lesions under control of normal p53 gene would be involved in apoptosis [3]. Various stimuli, such as: cytotoxic stimuli, ionizing and UV radiation, might initiate activation of normal p53 gene, through realizing its tumor suppressor func- tion. Moreover, cells with mutated p53 gene treated with genotoxic agents, could pass through cell cycle uncontrolled, and consequently numerous lesions in DNA might be accumulated. The most common p53 gene mutations are point mutations in exons 5, 6, 7, and 8 .

The aim of this study was to determine the frequency of p53 gene mutation, i.e. the role of this gene in pathogenesis of oral squamous cell carcinoma.

\section{MATERIALS AND METHODS}

A genomic DNA isolated from paraffin blocks of oral SCCs was used in this study. The specimens of tumor tissue after histopathology analysis precisely were cut out, separated from surrounding normal tissue and contributed to extraction of DNA using phenol/chloroform method.

From the 60 analyzed OSCCs, the most of them (26) were located in lower lip (43\%), than, with decreased frequency, in the following region: tongue - 16 (26.7\%), floor of mouth $-8(13 \%)$, bucal mucosa $-3(5 \%)$, mandibula $-3(5 \%)$ and 1 sample was obtained from other region of oral cavity. Using clinical parameters TNM status was determined (Table 1). Also, the degree of cell differentiation was estimated in all tumor specimens, using grading classification: G1 - well; G2 - moderate; G3 - poor; G4 undiferentiated. 45 out of 60 were primary tumors, and 15 were recurring. According to anamnesis data, analyzed 
Table 1. Distribution of oral squamocellular carcinomas in relation to TNM status and grade of diferentiation

Tabela 1. Raspodela oralnih skvamocelularnih karcinoma na osnovu TNM statusa i stepena diferencijacije

\begin{tabular}{|l|r|c|}
\hline \multicolumn{2}{|l|}{$\begin{array}{l}\text { TNM classification } \\
\text { TNM klasifikacija }\end{array}$} & $\begin{array}{c}\text { Number of samples } \\
\text { Broj uzoraka }\end{array}$ \\
\hline \multirow{3}{*}{$\begin{array}{l}\text { Type of invasion } \\
\text { Tip invazije }\end{array}$} & $\mathrm{T} 1(<2 \mathrm{~cm})$ & 3 \\
\cline { 2 - 3 } & $\mathrm{T} 2(2-4 \mathrm{~cm})$ & 24 \\
\cline { 2 - 3 } & $\begin{array}{r}\text { T4 (infiltrative) } \\
\text { T4 (infiltrativni) }\end{array}$ & 7 \\
\hline $\begin{array}{l}\text { Lymph node metastasis } \\
\text { Regionalna metastaza }\end{array}$ & $\mathrm{N} 0$ & 49 \\
\hline \multirow{2}{*}{$\begin{array}{l}\text { Metastasis } \\
\text { Udaljena metastaza }\end{array}$} & $\mathrm{N} 1$ & 11 \\
\hline \multirow{3}{*}{$\begin{array}{l}\text { Degree of grading } \\
\text { Gradus }\end{array}$} & $\mathrm{M} 0$ & 60 \\
\cline { 2 - 3 } & $\mathrm{G} 1$ & 0 \\
\cline { 2 - 3 } & $\mathrm{G} 2$ & 7 \\
\hline
\end{tabular}

specimens were dominantly obtained from older male patients, i.e. 33 patients had more than 33 years, while 47 were male.

The presence of point mutation in exon 5, 6, 7, and 8 , using polymerase chain reaction (PCR) and single strand conformation polymorphism (SSCP) method, was analyzed in all SCCs tumor specimens. Point mutations could be detected by means of SSCP, according to mobility of the single strand of DNA in nodenaturating environment. To confirm mutations detected by SSCP method, 5 specimens underwent to sequencing of exon 5 on $\mathrm{ABI}$ Prism 310 Genetic Analyzer.
Before performing sequencial analysis, using Qiagen kit, PCR amplicon was cleaned. PCR reaction mixture consisted of the following components: BigDye Terminator $3.1(8 \mu \mathrm{l})$, PCR amplicon-exon 5 (10 ng), ,forward” primer 5'TTCCTCTTCCTACAGTACTC3' (3.2 pmol) and $\mathrm{H}_{2} \mathrm{O}$ (to $20 \mu \mathrm{l}$ ). PCR reaction was performed as follows: initial denaturation at $96^{\circ} \mathrm{C}$ ( 1 minute) and 25 cycles of amplification at $96^{\circ} \mathrm{C}(10$ seconds $), 50^{\circ} \mathrm{C}$ (5 seconds) and $60^{\circ} \mathrm{C}$ (4 minutes). After PCR reaction, samples were treated with isopropanol to discard not incorporated nucleotide, than mixed with formamid and in the next step were denaturated at $96^{\circ} \mathrm{C} 2$ minutes. Following denaturation, samples were sequenced in ABI capillary system. Obtained sequences were compared with base of nucleotide sequence - NCBI GenBank.

\section{RESULTS}

Mutational analyses of p53 gene in exons 5, 6, 7 and 8, showed the presence of point mutation in $60 \%$ of analyzed samples. Summarizing all mutations of $\mathrm{p} 53$ gene, 8 mutation were detected in exon 5, 12 in exon 6, 16 in exon 7 and 13 in exon 8 . A higher frequency of mutations was obtained in exons 7 and 8 (60\%), than in exon 5 and 6 . The presence of point mutations in exon 5 of p53 gene, detected by SSCP technique, was confirmed by sequencing of the 5 randomly chosen samples (Table 2).

By analyzing distribution of oral SCCs with p53 mutation in relation to clinical and histopathological parame-

Table 2. Nucleotide sequence of exon 5, p53 gene

Tabela 2. Nukleotidne sekvence egzona 5 gena p53

\begin{tabular}{|c|c|}
\hline \multirow{2}{*}{$\begin{array}{l}\text { Sample } 1 \\
\text { Uzorak } 1\end{array}$} & $\begin{array}{l}\text { CTCCCCGCCCTGGCACCCGCGTCCTGCGCCATGGCCATCTACAAGCATGTCACAGCACATGACGGAGGTTGTGAGGCGCTGCCCC } \\
\text { CACCATGAGCGCTGCTCAGATAGCGATGGTGAGCAGCTGGGGCTGGAGAGACGACAGGGCTGGTTGCCCAGGGTCCCCAGGCCT } \\
\text { CTGATTCCTCACTGATTGCTCTTAGGTCTGGCCCCTCCTCAGCATCTTATCCGAGTGGAAGGAAATTTGCA }\end{array}$ \\
\hline & $\begin{array}{l}\text { Insertion } \mathbf{T} \text { in codon 33, CGC Insertion } \mathbf{T} \text { in codon 40, CAG } \\
\text { Insercija } \mathrm{T} \text { u kodonu 33, CGC Insercija } \mathrm{T} \text { u kodonu 40, CAG }\end{array}$ \\
\hline \multirow{3}{*}{$\begin{array}{l}\text { Sample } 2 \\
\text { Uzorak } 2\end{array}$} & $\begin{array}{l}\text { GACTTCGATGGAACAGAAATTTGCATTTGCCAACTGGCCAAGACCTGCCCTGTGCAGCTGTGGGTTTGATTCCACACCCCCICCC } \\
\text { GGCACCCGCGTCCGCGCCATGGCCATCTACAAGCAGTCACAGCACATGACGGAGGTTGTGAGGCGCTGCCCCCACCATGAGCGCT } \\
\text { GCTCAGATAGCGATGGTGAGCAGCTGGGGCTGGAGAGACGACIGGGCTGGTTGCCCAGGGTCCCCAGGCCTCTGATTCCTCACT } \\
\text { GATTGCTCTTAGGTCTGGCCCCTCCTCAGCATCTTATCCGAGTGGAAGGAAATTTGCA }\end{array}$ \\
\hline & $\begin{array}{l}\text { Supstitution in codon } 27, \mathrm{CC} \underline{G} \rightarrow \mathrm{CC} \underline{\mathbf{I}}(\text { Pro } \rightarrow \text { Pro) } \\
\text { Supstitucija u kodonu } 27, \mathrm{CC} \underline{\underline{G}} \rightarrow \mathrm{CC} \underline{\mathbf{I}} \text { (Pro } \rightarrow \text { Pro) }\end{array}$ \\
\hline & $\begin{array}{l}\text { Supstitution in intron, } A \rightarrow T \\
\text { Supstitucija } A \rightarrow T \text { intronu }\end{array}$ \\
\hline \multirow{3}{*}{$\begin{array}{l}\text { Sample } 3 \\
\text { Uzorak } 3\end{array}$} & $\begin{array}{l}\text { TTTCGATGGAGGGACTGCATGCTTAGTTCGGGGAGACCTGGAATAGTCCTGGAAGTTTGGGGGGTTGAAAAGCCCACCCCCGCCC } \\
\text { GGCACCCGCGTCCGCGCCATGGCCATCTACAAGCAGTTACAGCACATGACGGAGGTTGTCAGGCGCTGCCCCCACCATGAGCGCT } \\
\text { GCTCAGATAGCGATGGTGAGCAGCTGGGGCTGGAGAGACGACAGGGCTGGTTGCCCAGGGTCCCCAGGCCTCTGATTCCTCACTG } \\
\text { ATTGCTCTTAGGTCTGGCCCCTCCTCAGCATCTTATCCGAGTGGAAGGAAATTTGCA }\end{array}$ \\
\hline & $\begin{array}{l}\text { Supstitution in codon } 41, \text { TCA } \rightarrow \text { TTA }(\mathrm{Ser} \rightarrow \text { Leu) } \\
\text { Supstitucija u kodonu } 41, \text { TCA } \rightarrow \text { TTA (Ser } \rightarrow \text { Leu) }\end{array}$ \\
\hline & $\begin{array}{l}\text { Supstitution in codon } 48, \mathrm{GTG} \rightarrow \mathrm{GTC}(\mathrm{Val} \rightarrow \mathrm{Val}) \\
\text { Supstitucija u kodonu } 48, \mathrm{GTG} \rightarrow \mathrm{GTC}(\mathrm{Val} \rightarrow \mathrm{Val})\end{array}$ \\
\hline \multirow[t]{2}{*}{$\begin{array}{l}\text { Sample } 4 \\
\text { Uzorak } 4\end{array}$} & $\begin{array}{l}\text { GACTTCGATGGAACAGAAATTTGCATTTGCCAACTGGCCAAGACCTGCCCTGTGCAGCTGTGGGTT >AT>CC ACACCCCCGCCCG } \\
\text { GCACCCGCGTCCGCGCCATGGCCATCTACAAGCAGTCACAGCACATGACGGAGGTTGTGAGGCGCTGCCCCCACCATGAGCGCTG } \\
\text { CTCAGATAGCGATGGTGAGCAGCTGGGCTGGAGAGACGACAGGGCTGGTTGCCCAGGGTCCCCAGGCCTCTGATTCCTCACTGA } \\
\text { TTGCTCTTAGGTCTGGCCCCTCCTCAGCATCTTATCCGAGTGGAAGGAAATTTGCA }\end{array}$ \\
\hline & $\begin{array}{l}\text { Deletion in codon 23, } \text { GAT and codon, } 24 \text { TCC } \\
\text { Delecija na kodonu } 23, \underline{\text { GAT }} \text { i kodonu } 24, \underline{\text { ICC }}\end{array}$ \\
\hline \multirow[t]{2}{*}{$\begin{array}{l}\text { Sample } 5 \\
\text { Uzorak } 5\end{array}$} & $\begin{array}{l}\text { GACTTCGATGGAACAGAAATTTGCATTTGCCAACTGGCCAAGACCTGCCCTGTGCAGCTGTGGGTITTGATTCCACACCCCCGCCC } \\
\text { GGCACCCGCGTCCGCGCCATGGCCATCTACAAGCAGTCACAGCACATGACGGAGGTTGTGAGGCGCTGCCCCCACCATGAGCGCT } \\
\text { GCTCAGATAGCGATGGTGAGCAGCTGGGGCTGGAGAGACGACAGGGCTGGTTGCCCAGGGTCCCCAGGCCTCTGATTCCTCACTG } \\
\text { ATTGCTCTTAGGTCTGGCCCCTCCTCAGCATCTTATCCGAGTGGAAGGAAATTTGCA }\end{array}$ \\
\hline & $\begin{array}{l}\text { Insertion T in codon 22, GTT } \\
\text { Insercija T u kodonu 22, GTT }\end{array}$ \\
\hline
\end{tabular}


ters, higher frequency of mutation was observed in moderate/poor differentiated carcinoma as well as in the higher clinical stages of the carcinoma. The difference in distribution of p53 affected gene was not established between primary and recurring carcinoma, and also between carcinoma with and without metastasis in the lymphatic nodes.

\section{DISCUSSION}

It is known fact that about $95 \%$ mutations that lead to inactivation of p53 gene are located in highly conserved, DNA binding domain (from 5 to 9 exon). The aim of this study was to analyze a role of exon 5, 6, 7 and 8 in mutational spectra of $\mathrm{p} 53$ gene in oral SCC. According to these analyses, a higher frequency of mutations was observed in exons 7 and $8(60 \%)$ than in exons 5 and 6 , what is in agreement with results of other authors [4]. In order to confirm and detect type of mutations, sequencing analysis of exon 5 was done for five specimens. Interestingly, different types of point mutations were located at nucleotide $G$ in particulary codon. In various tumor samples substitution $G \rightarrow T$ and $G \rightarrow C$, deletion $G$ and insertion at guanine $(G)$ nukleotide were found. Whatever the type of the detected mutations and their effect to structure of altered p53 protein, changes in nucleotide sequence were dominantly present at $\mathrm{G}$. The numerous studies that investigated a role of carcinogenic agens in development of the head, neck and lung carcinoma, showed that carcinogens present in tobacco smoke bind to $\mathrm{G}$ and frequently induce point mutation in DNA binding region of p53 gene $[5,6]$. Also, many studies proved the connection between carcinogenic factors (UV radiation, alcohol, exposure to phys$\mathrm{ical} /$ chemical mutagenes) and specific muational spectra of 553 gene $[7,8]$.

In accordance with the most of reported data in the world, this study showed $60 \%$ of analyzed carcinoma with p53 gene mutation [9]. The relationship between p53 mutation and its altered protein was shown in many immunohistochemical studies by detecting mutated p53 protein with prolonged half-life in nucleus or citoplasm [10]. Beside to histopathological and clinical parameters, mutational status of p53 gene may have a role as an additional prognostic marker in oral SCCs. It is confirmed that tumors with p53 mutation are more resistent to radio- and chemotherapy, due to absence of p53-induced apoptosis [11]. On the other hand, some data showed no association between normal p53 gene and better therapy response. Therefore, it is possible that many molecules are included in apoptotic pathway [12].

In this study, a higher incidence of p53 mutation in higher clinical stages was shown, indicating its important role in patogenesis of oral carcinoma. Opposite to these results, absence of p53 mutation in $40 \%$ cases, could be attributed to p53-independent mechanism of carcinogenesis.

\section{CONCLUSION}

A high incidence of p53 mutation in analyzed samples without doubt emphasized its important role in development and progresion of OSCC.

\section{ACKNOWLEDGMENT}

This study was financed by Serbian Ministry of Science and Technology (Grant No. 1454042).

\section{REFERENCES}

1. Greenlee RT, Murray T, Bolden S, Wingo PA. Cancer statistics 2000. CA Cancer J Clin. 2000; 50:7-33.

2. Yao L, Iwai M, Furuta I. Correlation of bcl2 and $p 53$ expression with the clinico pathological features in tongue squamous cell carcinomas. Oral Oncol. 1999; 35:56-62.

3. Zhang $Y$, Xiong $Y$, Yarbrough WG. ARF promotes MDM2 degradation and stabilizes p53: ARF-INK4a locus deletion impairs both the Rb and $\mathrm{p} 53$ tumor suppression pathways. Cell. 1998; 92:725-34.

4. Chaves A, Cherubini K, Herter N, Furian R, Santos D, Squier C, et al. Characterization of 553 gene mutation in a Brazilian population with oral squamous cell carcinomas. Int J Oncol. 2004; 24:295-303.

5. Boyle JO, Hakim J, Koch W, Van der Riet P, Hruban RH, Roa RA, et al. The incidence of p53 mutations increases with progression of head and neck cancer. Cancer Res. 1993; 53:4477-80.

6. Denissenko MF, Pao A, Tang M, Pfeifer GP. Preferential formation of benzo[a]pyrene adducts at lung cancer mutational hotspots in p53. Science. 1996; 274:430-2.

7. Kress S, Sutter C, Strickland PT, Mukhtar H, Schweizer J, Schwarz M. Carcinogen-specific mutational pattern in the p53 gene in ultraviolet $B$ radiation-induced squamous cell carcinomas of mouse skin. Cancer Res. 1992; 52:6400-13.

8. Regezi JA, Jordan RC. Oral cancer in the molecular age. J Calif Dent Assoc. 2001; 29:578-84.

9. Bosch FX, Ritter D, Enders C, Flechtenmacher C, Abel U, Dietz A, et al. Head and neck tumor sites differ in prevalence and spectrum of p53 alterations but these have limited prognostic value. Int J Cancer. 2004; 111:530-8.

10. Nagler RM, Kerner H, Laufer D, Ben-Elizer S, Minkov I, Itzhak OB. Squamous cell carcinoma of the tongue: the prevalence and prognostic roles of $\mathrm{p} 53, \mathrm{Bcl}-2, \mathrm{c}-\mathrm{erbB} 2$ and apoptotic rate as related to clinical and pathological characteristic in a retrospective study. Cancer Letters. 2002; 186:137-50.

11. Cabelguenne A, Blons H, de Waziers I, Carnot F, Houllier AM, Soussi T, et al. p53 alterations predict tumor response to neoadjuvant chemotherapy in head and neck squamous cell carcinoma: a prospective series. J Clin Oncol. 2000; 18:1465-73.

12. Gudkov AV, Komarova EA. The role of p53 in determining sensitivity to radiotherapy. Nat Rev Cancer. 2003; 3:117-29.
Address for correspondence
Branka Popović
Institute for Human Genetics
School of Dentistry
Dr Subotića 1, 11000 Belgrade
Serbia
Phone: +381 (0)112683943
Email: brankapo@verat.net 


\title{
Mutacioni status gena p53 u oralnim skvamocelularnim karcinomima
}

\author{
Branka Popović1, Biljana Jekić2 ${ }^{2}$ Drago Jelovac 3 , Ivana Novaković ${ }^{2}$ \\ ${ }^{1}$ Institut za humanu genetiku, Stomatološki fakultet, Univerzitet u Beogradu, Beograd, Srbija; \\ Institut za humanu genetiku, Medicinski fakultet, Univerzitet u Beogradu, Beograd, Srbija; \\ ${ }^{3}$ Klinika za maksilofacijalnu hirurgiju, Stomatološki fakultet, Univerzitet u Beogradu, Beograd, Srbija
}

\begin{abstract}
KRATAK SADRŽAJ
Uvod TP53 je ključni tumor-supresorski gen uključen u patogenezu oralnih skvamocelularnih karcinoma (OSCK). Proteinski proizvod gena p53 zadužen je za kontrolu ćelijskog ciklusa i apoptozu, a mutacije u TP53 mogu dovesti do nekontrolisane proliferacije ćelija. Cilj ovog rada je bio da se utvrdi zastupljenost tačkastih mutacija u regionu gena p53 koji se vezuje za DNK, odnosno proceni uloga ovoga gena u patogenezi OSCK.

Materijal i metode rada U 60 uzoraka OSCK su korišćenjem metode lančane reakcije polimeraze i polimorfizma jednolančanih fragmenata DNK (PCR-SSCP) ispitane tačkaste mutacije u egzonima 5, 6, 7 i 8 gena p53. Pet slučajno odabranih uzoraka u kojima je otkrivena mutacija naknadno je podvrgnuto sekvenciranju radi potvrde validnosti metode PCR-SSCP.

Rezultati Tačkaste mutacije u nekom od analiziranih egzona gena p53 utvrđene su u 60\% uzoraka OSCK. Veća učestalost mutacija zabeležena je u egzonima 7 i 8 . Sekvenciranje je potvrdilo mutacije otkrivene metodom SSCP. Studija asocijacije pokazuje povećanje broja mutacija gena p53 kod slabo diferenciranih i karcinoma viših kliničkih stadijuma.
\end{abstract}

Zaključak Gen p53, jedan od glavnih kontrolora ćelijskog ciklusa, ima značajnu ulogu i u patogenezi karcinoma oralne duplje.

Ključne reči: gen p53; tačkaste mutacije; oralni skvamocelularni karcinom

\section{UVOD}

Prema statističkim nalazima u svetu, skvamocelularni karcinomi glave i vrata (SCK) se na skali incidencije svih tumora kod ljudi nalaze na šestom mestu, pri čemu je 50\% tumora ovog regiona lokalizovano u oralnoj regiji. Uprkos pomaku u prevenciji i lečenju ostvarenom poslednjih decenija u pogledu petogodišnje stope preživljavanja bolesnika (koja je oko 50\%), značajan napredak još nije ostvaren [1]. Skromna simptomatologija, brz rast i rane metastaze su razlozi nepredvidljivog kliničkog toka bolesti. Preventivna primena različitih skrining-metoda i uvođenje molekularnogenetičkih analiza u otkrivanje karcinoma u pretkliničkoj, asimptomatskoj fazi mogli bi svakako obezbediti i bolju prognozu.

Jedan od ključnih molekularnogenetičkih markera koji je uključen u kontrolu proliferacije kod oko $60 \%$ tumora glave i vrata je tumor-supresorski gen p53 [2]. Do gubitka normalne funkcije ovoga gena može doći usled dejstva različitih kancerogenih agensa (duvanski dim, alkohol,...) kojima je oralna mukoza često izložena. TP53 gen je označen još i kao „čuvar genoma” i ima ulogu u zaustavljanju proliferacije ćelija sa genskim lezijama, kako bi se popravila oštećenja naslednog materijala. U suprotnom, ćelije s neoporavljenim lezijama treba da se podvrgnu programu apoptoze [3]. Različiti stimulusi, kao što su dejstvo citotoksičnih antitumorskih agensa, jonizujućeg i ultraljubičastog zračenja, mogu takođe dovesti do aktivacije normalnog gena p53, odnosno do realizacije njegove tumor-supresorske funkcije. Međutim, ćelije s mutiranim genom p53 koje su izložene dejstvu genotoksičnih agensa nekontrolisano će prolaziti kroz ćelijsku ciklus, što za posledicu ima nagomilavanje brojnih lezija na DNK. Najčešći tip genskih mutacija koje pogađaju gen p53 su tačkaste mutacije u egzonima 5, 6, 7 i 8 .

Cilj rada je bio da se utvrdi zastupljenost tačkastih mutacija u regionu gena p53 koji se vezuje za DNK, odnosno proceni uloga ovoga gena u patogenezi oralnih skvamocelularnih karcinoma (OSCK).

\section{MATERIJAL I METODE RADA}

U studiji je korišćena genomska DNK izolovana iz parafinskih blokova OSCK. Uzorci tumorskog tkiva su nakon histopatološke analize precizno isečeni i odvojeni od okolnog ukalupljenog normalnog tkiva, a zatim podvrgnuti metodi fenol-hloroform ekstrakcije DNK.

Od ukupnog broja analiziranih OSCK (60) najviše tumora (26) je bilo lokalizovano na donjoj usni (43\%); slede lokalizacije na jeziku - $16(26 \%)$, podu usta - $8(13 \%)$, bukalnoj sluzokoži - 3 (5\%) i mandibuli - 3 (5\%). Po jedan uzorak (1\%) je dobijen iz predela maksile, gingive, orofarinksa i mekog nepca. Za sve OSCK je na osnovu kliničkih parametara definisan tzv. TNM status (veličina tumora, lokalne i udaljene metastaze) (Tabela 1). Pored određivanja TNM statusa, klasifikacija karcinoma je izvršena i na osnovu stepena diferencijacije malignih ćelija, i to na četiri stupnja: G1 - dobro diferencirane, G2 srednje diferencirane, G3 - slabo diferencirane i G4 - nediferencirane ćelije. Od ukupnog broja uzoraka, 45 su predstavljali primarne tumore, dok su 15 bili recidivi. Posmatrajući starosnu i polnu strukturu bolesnika, dominirali su stariji muškarci, pri čemu su 33 bolesnika imala više od 60 godina, a ukupno je bilo 47 muškaraca.

Kod svih OSCK su analizirane tačkaste mutacije u egzonima 5, 6, 7 i 8 gena p53 metodom lančane reakcije polimeraze (engl. polymerase chain reaction - PCR) i polimorfizma jednolančanih fragmenata DNK (engl. single strand conformation polymorphism - SSCP). SSCP se zasniva na elektroforetskoj pokretljivosti jednolančane DNK u nedenaturišućoj sredini. Kako bi se potvrdile mutacije otkrivene ovom metodom, kod pet uzoraka je dodatno sekvenciran egzon 5 gena p53 na aparatu ABI Prism 310 Genetic Analzyer.

Pre sekvenciranja PCR amplifikati su prečišćeni primenom kita Qiagen. Reakcionu smesu PCR činile su sledeće komponente: BigDye Terminator 3.1 ( $8 \mu \mathrm{l})$, PCR amplifikat egzon 5 (10 ng), ,uzvodni” prajmer 5'TTCCTCTTCCTACAGTACTC3' 
(3,2 pmol) i voda (do $20 \mu \mathrm{l})$. Program PCR za sekvenciranje bio je sledeći: inicijalna denaturacija na $96^{\circ} \mathrm{C}$ (jedan minut) i 25 ciklusa amplifikacije na $96^{\circ} \mathrm{C}$ (10 sekundi), $50^{\circ} \mathrm{C}$ (pet sekundi) i $60^{\circ} \mathrm{C}$ (četiri minuta). Nakon PCR uzorci su prečišćeni izopropanolom da bi se odstranili neinkorporisani obeleženi nukleotidi, a zatim je dodat formamid, posle čega su uzorci denaturisani na $96^{\circ} \mathrm{C}$ dva minuta. Posle denaturacije uzorci su postavljeni u ABI (engl. applied biosystems), kapilarni sistem za sekvenciranje. Dobijene sekvence upoređene su s Međunarodnom bazom podataka (NCBI GenBank).

\section{REZULTATI}

Mutacionom analizom tačkaste mutacije su ustanovljene u $60 \%$ analiziranih uzoraka OSCK. Otkriveno je osam mutacija u egzonu 5, 12 u egzonu 6, 16 u egzonu 7 i 13 u egzonu 8. U 13 uzoraka otkrivene su po dve mutacije u različitim egzonima. Veća učestalost mutacija dobijena je u egzonima 7 i 8 (60\%). Tačkaste mutacije u egzonu 5 gena p53, otkrivene pomoću SSCP, potvrđene su direktnim sekvenciranjem pet slučajno odabranih uzoraka (Tabela 2).

Analizirajući raspodelu OSCK sa mutacijom gena p53 u odnosu na kliničke i histopatološke parametre, ustanovljena je veća učestalost mutacija kod srednje i slabo diferenciranih i karcinoma viših kliničkih stadijuma. Razlika u stopi mutacija nije ustanovljena ni između primarnih karcinoma i recidiva, niti između karcinoma sa metastazama u limfnim čvorovima i karcinoma bez ovih metastaza.

\section{DISKUSIJA}

Kako je 95\% mutacija gena p53 koje se odražavaju na inaktivaciju proteina p53 locirano u visoko konzerviranom regionu koji se vezuje za DNK, cilj ove studije bio je da se analizira udeo egzona 5, 6, 7 i 8 u mutacionom spektru gena p53 u OSCK. Ustanovljena je veća učestalost mutacija u egzonima 7 i 8 (60\%), što su zabeležili i drugi autori [4]. Radi potvrde zastupljenosti i određivanja tipa mutacija, kod pet uzoraka je sekvenciran egzon 5. Uočeno je da se različiti tipovi tačkastih mutacija najčešće dešavaju na nukleotidu $\mathrm{G}$ određenog kodona. Tako se kod različitih uzoraka otkrivaju supstitucije $\mathrm{G} \rightarrow \mathrm{T}$ i $\mathrm{G} \rightarrow \mathrm{C}$, delecija $\mathrm{G}$ i insercija ispred G. Dakle, bez obzira na tip mutacije i njen efekat na strukturu izmenjenog proteina p53, promene unutar gena se dešavaju u nivou nukleotida G. Brojne studije koje su ispitivale ulogu kancerogenih agensa u razvoju karcinoma glave i vrata i pluća pokazale su da mutageni duvana vezivanjem za nukleotid $\mathrm{G}$ izazivaju tačkaste mutacije, najčešće u region gena p53 koji se vezuje za DNK $[5,6]$. U mnogim istraživanjima je takođe dokazana veza između dejstva mutagenih faktora, kao što su ultraljubičasto zračenje, zloupotreba alkohola, izlaganje fizičkim i hemijskim mutagenima na radnom mestu, i specifičnog mutacionog spektra gena p53 [7, 8].

U skladu s većinom rezultata studija publikovanih u svetskoj literaturi, u ovom istraživanju su u $60 \%$ analiziranih karcinoma potvrđene mutacije gena p53 [9]. Da su mutacije ovoga gena praćene i izmenjenim proteinom $\mathrm{p} 53$ pokazuju različite imunohistohemijske studije koje su otkrile mutirani protein p53 u jedru ili citoplazmi usled njegovog prolongiranog poluživota [10]. Dakle, pored histopatoloških i kliničkih parametara, mutacioni status gena p53 može imati ulogu dodatnog prognostičkog pokazatelja kod OSCK. Neki autori su utvrdili da su karcinomi sa mutacijom gena 553 rezistentniji na zračnu terapiju i hemioterapiju usled inhibicije mehanizma apoptoze p53 [11]. Ipak, još ima dosta kontradiktornosti koje se odnose na vezu između prisustva normalnog proteina p53 i odgovarajućeg terapijskog odgovora zbog mogućnosti da se apoptoza zaustavi na više različitih signalnih puteva [12].

\section{ZAKLJUČAK}

Visoka učestalost mutacija gena p53 u ispitanim uzorcima nesumnjivo ukazuje na važnu ulogu ovog kontrolora ćelijskog ciklusa u nastanku i progresiji karcinoma oralne regije.

\section{NAPOMENA}

Rad je finansiralo Ministarstvo za nauku i tehnološki razvoj Republike Srbije (projekat br. 1454042). 